\title{
Sponsored research but with strings attached
}

\section{Brussels}

For the time being, the cornerstone of the Commission's effort in research is the conviction that European industry must be helped to be more competitive with the outside world, and that the sponsorship of industrial research is the best way of doing that. How well is it doing?

The best-known and the first major collaborative programme is that known as ESPRIT, intended when launched in 1984 as a ten-year programme of research and development in information technology, financed on a cost-sharing basis between the Commission and collaborating companies. (The Commission's share is more than 300 million ECU a year.)

ESPRIT inevitably became the model for later programmes. One of these, BRITE, is a cost-sharing programme aimed at improving the production technology and thus the competitiveness of small and medium-sized enterprises, SMEs in Eurospeak, on which the Commission has spent 175 million ECU on 230 projects since 1985 .

The diversity of these programmes is widely remarked upon, as is the enthusiasm of those who take part. ESPRIT, for example, covers everything from the design of the semiconductor elements of computers to the development of software and hardware for desk-top publishing.

Out of the first of these interests has grown the programme called JESSI on the development of submicron computer chips (see Nature 337, 682; 23 February 1989). Garcia Aroyo, the DGXII director with responsibility for technological research, appears sanguine at the prospect that his colleagues will soon be labouring under $800-900$ applications for funds to support industrial research in production technology and materials development. BRITE was merged with a parallel programme on materials development from the beginning of this year; the closing date for applications under the combined programme (on which the Commission will spend 500 million ECU in the next four years) is 12 May.

The rules are the same. Successful applications must involve industrial companies from more than one European country (and not more than two-thirds of the total grant can finish up in any one country). Companies must be genuinely independent of each other (which means that the collaboration cannot simply be a means by which one company and its subsidiaries elsewhere collaborate on work they might have done anyway). A small proportion of the funds (up to 7 per cent) may be spent on proposals by university consortia for generic investigations provi- ded that the proposals are endorsed by industrial companies.

Projects must be original and preferably applicable in more than one industry. Interestingly, companies from countries in the European Free Trade Area (Norway, Sweden, Finland, Austria and Switzerland) may take part, but cannot receive Commission funds (and may have to contribute modestly to administrative costs). Research projects must be "pre-competitive". This time round, there is also a scheme for providing up to 75 per cent of the cost of a feasibility study (up to a maximum of $25,000 \mathrm{ECU}$ ).

This year's programme has plainly been much influenced by the report of an influential evaluation panel under Yves Farge, vice-president for research and development at the French company Pechiney et Cie., which reported last July. That panel, for example, recommended the merging of the BRITE and advanced materials (EURAM) programmes.

The Commission has also, in a late amendment of its proposals, followed the recommendation that universities collaborating in industrial projects should be recompensed by the Commission for the full cost of their work. (Under the old arrangements, industrial partners would usually pay the other half of the cost.)

Of the questions raised by the Farge committee, those implicitly answered so far are procedural in character. More fundamental issues are unresolved, conspicuously the panel's concern at what it called a "major contradiction" in the Commission's restriction of the programmes it would support to those judged "pre-competitive".

The principle is that the Commission will not support industrial development work leading directly to marketable products or usable processes, but only industrial research of a generic character on which more pointed research programmes can be based. The experience of the BRITE programme apparently showed that some "excellent projects" were not supported because they were judged to be "too competitive", but that the fear of falling into that trap pushed other applicants "upstream", with the consequence that the industrial interest of their projects was diminished. This complaint is also a dilemma for the Commission. Relaxing the pre-competitive rule would place the Commission in the position of providing direct support for commercial development by individual companies.

But the Farge panel points to the recent amendment of anti-trust legislation in the United States allowing research and development partnerships, and says that

\section{Rooting for grants}

Self-evaluation is the price the Commission has to pay for its existence. Councils of ministers insist upon it. But one official describes the process as the administrative equivalent of repeatedly digging up a newly planted tree to see whether its roots are growing.

The Farge panel, for example, was in a position to attempt to estimate the economic benefits that would flow from the two first phases of the BRITE programme by means of a questionnaire to the industrial companies participating.

Among other things, participants were asked to estimate the degree to which the project on which they were working would increase their annual turnover, from which the Farge panel estimated that the total increase of annual production resulting from BRITE projects would exceed 2,000 million ECU. But the panel also noted that the same companies planned to commit only "modest" sums to the further development of the outcomes of their projects, for which reason it suggests that the economic benefits expected of the projects should "be viewed with some caution".

"the law should be the servant of the Community, not its master". The pane also complains that the Commission, in its management of its research programmes, has not been sufficiently explicit about its objectives.

More generally, the panel pointed out that it had not been able to put the BRITE programme "into perspective in a coherent approach to an industrial research and development policy". This criticism appears only partly to have been met in the new phase of the programme.

BRITE covered nine disparate fields such as computer-aided design (CAD) and production technology for flexible materials (mostly textiles). Its successor has only five broad headings, which may be thought a step towards the definition of a strategy. Three are aeronautics, advanced materials and design, quality and reliability. There are also subprogrammes for the application of known manufacturing technology and the development of novel techniques and processes.

The Farge panel was also concerned that the Commission's own judgement of which projects to support is excessively technical, and insufficiently informed by business considerations. (The Commission's technical staff do get high marks for competence and enthusiasm.) The consequence, the panel said last July, is that there was too much "technology push" and not enough "market pull" in the BRITE programme.

In the nature of things at Brussels, it is too soon to know how the next evaluation panel will rate the achievements of the new programme. Much will depend on how the Commission's officials adapt their choices to the Farge's panel's pleas. The test will be whether Europe's middle-sized businesses are markedly more efficient. $\square$ 